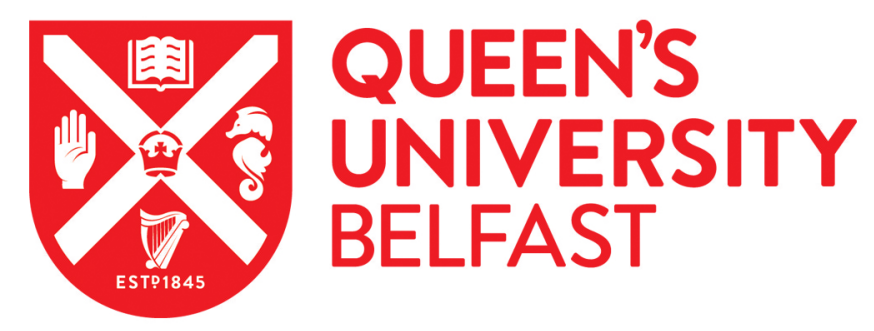

\title{
Who Knows What's Going On? Mapping New Security Landscapes in Contemporary Espionage Fiction
}

Pepper, A. (2015). Who Knows What's Going On? Mapping New Security Landscapes in Contemporary Espionage Fiction. Journal of American Studies, 49(4), 775-792. https://doi.org/10.1017/S0021875815001711

Published in:

Journal of American Studies

Document Version:

Peer reviewed version

Queen's University Belfast - Research Portal:

Link to publication record in Queen's University Belfast Research Portal

Publisher rights

Copyright ( Cambridge University Press and British Association for American Studies 2015

\section{General rights}

Copyright for the publications made accessible via the Queen's University Belfast Research Portal is retained by the author(s) and / or other copyright owners and it is a condition of accessing these publications that users recognise and abide by the legal requirements associated with these rights.

Take down policy

The Research Portal is Queen's institutional repository that provides access to Queen's research output. Every effort has been made to ensure that content in the Research Portal does not infringe any person's rights, or applicable UK laws. If you discover content in the Research Portal that you believe breaches copyright or violates any law, please contact openaccess@qub.ac.uk. 


\section{WHO KNOWS WHAT'S GOING ON?:}

\section{MAPPING NEW SECURITY LANDSCAPES IN CONTEMPORARY ESPIONAGE FICTION}

The espionage novel is premised on a world of intrigue, secrets, clandestine affiliations, paranoia and covert political machinations, in which the actions of a representative figure - the spy - evoke "the shadowy underpinnings - secret committees and covert plots - that keep the state functioning." ${ }^{1}$ It is best understood as a type of cultural fantasy, one that allows writer and reader to speculate on the obligations of citizenship and the complex relationship between private knowledge and public commitment. According to Allan Hepburn, the spy “may have his moments of revolt and anguish” and often seeks to pursue a private notion of justice in direct contravention of official wisdom, but this same figure "also knows that state power exists in and through his deeds."2 Referring to contemporary espionage narratives that specifically address the issue of security in the aftermath of the terrorist attacks of September 11 2011, Timothy Melley is even less equivocal: their “ideological function” is quite simply "to defend the operation of a Cold War security state in a post-Cold War climate.” ${ }^{3}$ For both Hepburn and Melley, the form and function of the espionage narrative, and the ambitions of its representative figure, are handcuffed to the state, and hence to an account of the "international" where states, and certainly states as powerful as the United States, dominate as Great Powers. The starting point for this article, looking at contemporary espionage fiction, is to question this basic assumption: that is, to ask what happens when it is no longer possible or sensible to assume that the state can successfully exercise control over a bounded, demarcated territory by means of a domestic security apparatus or that the state is the form of political authority in the international realm. Three questions follow. First, how is espionage fiction responding (or indeed not responding) to a deterritorialized international realm in which states operate, sometimes in consort with and sometimes in opposition to, a constellation of other forces (e.g. multinational corporations, international organized crime gangs)? Second, to what extent is the espionage novel - a genre seemingly bound up with these older notions

\footnotetext{
${ }^{1}$ Allan Hepburn, Intrigue: Espionage and Culture (New Haven, CT: Yale University Press, 2005), 277.

${ }^{2}$ Ibid., 277

${ }^{3}$ Timothy Melley, Covert Sphere: Secrecy, Fiction and the National Security State (Ithaca, NY: Cornell University Press, 2012), 43.
} 
of state sovereignty and premised on the geopolitical struggles between states - able to formally adapt to changing historical circumstances in which new security practices trouble, exceed and destabilize sovereign statehood? And third, what expectations should we place on espionage fiction not simply to reflect reality, or indeed to register changes in this reality through subtle shifts in form and structure, but rather to directly engage with, and perhaps even intervene in, political questions about how power works and what if anything can be done to confront it. ${ }^{4}$

My case studies are a trilogy of novels by Olen Steinhauer - The Tourist (2009), The Nearest Exit (2010) and An American Spy (2011) - featuring Milo Weaver, a spy who works for a clandestine CIA department tasked with carrying out ethically dubious activities across the globe; Steinhauer's short story “You Know What’s Going On?” (2011); and Richard House’s The Kills (2013) which deals with a financial fraud committed by state proxies and private contractors during the US-led reconstruction of Iraq. It is not my intention to argue that these examples jettison the formal and thematic preoccupations of earlier espionage novels or the historical tradition that handcuffs the genre to the machinations of states. Steinhauer's work, as I'll show in the next section, partly reproduces one of the genre's central feature in the twentieth century: the spy's ambiguous relationship to the state. But while Hepburn and Melley both argue for the state as constitutive of the genre, even when the genre is questioning the state’s legitimacy or its authority, neither ask what happen when that foundational link between genre and state is fractured. In this article, I am most interested in exploring how, or how far, these examples of contemporary espionage fiction are able to address and negotiate the central features of the new security landscape. To do this, I want to focus on three particular re-articulations of power in the international sphere: first, how security threats are speculated, calculated and managed under a regime of risk assessment; second, how citizen-subjects and systems are made "resilient" so they can better adapt to global uncertainties; and, third, how the privatization of security practices exposes the

\footnotetext{
${ }^{4}$ One of the key starting points for this line of thinking of Jean-Paul Sartre's famous 1947 book What is Literature? in which he positing the figure of the committed or engaged writer and the idea that such a writer had a duty to take a stand against injustice and exploitation since to do nothing was effectively side with the status quo. In the context of the contemporary espionage novel the figure who best epitomises this “commitment” is John le Carré who has spoken out against the affront to liberty posed by the US-led securityintelligence nexus but his work, like that of Steinhauer and House, cannot simply oppose the political and security establishment because their protagonists are "insiders" who, while often critical of particular policies and practices, have to find ways of operating within state institutions and according to procedural norms.
} 
practices of government to the imperatives of the marketplace and the pursuit of profits. ${ }^{5}$ These three re-articulations map onto the three sections of this article, entitled speculation, resilience and profit. In each of these sections, and in the attendant works of fiction, there may be an element of socio-political criticism, albeit one circumscribed by the "insider" account of power we are given, but following Jacques Rancière’s assertion that "literature...does not perform political action, it does not creative collective forms of action, it contributes to the reframing of forms of experience," ${ }^{6}$ my emphasis is on the kind of insights into these newly emerging security practices that espionage fiction can give us, i.e. what is being "reframed," above and beyond what we can glean from historical accounts or sociological analyses.

The work of the espionage novel has always been speculative insofar as it is directed at staving off a threat, usually a specific threat, to the state and/or its national interests. In the context of the Cold War and the American espionage novel in particular, this threat was typically named as Communism and the spread of Soviet influence across the globe. More particularly the Communist enemy defined and gave shape to the narrative: the specific manifestation of the threat was identified, hunted down and ultimately vanquished, even if the security apparatus was shown to be inefficient (e.g. because of an unwieldy bureaucracy) or incompatible with the claims of individual liberty. As Melley argues about more recent adaptations of this formula, "[w]hen the state engages covertly with a distant and inscrutable enemy, both the state's enemies and its own methods become a source of mystery...speculation, and anxious projection." ${ }^{77}$ However generic constraints and narrative trajectory require that threats and enemies are dealt with in such a way as to buttress what Melley calls the imperatives of the US security state. What is different about the espionage fiction under scrutiny here is that, like the new security environment it seeks to reflect, it elevates the practice of speculation - of imagining and predicting what threats might exist - above the solutions that the genre typically provides. Simply put, it is impossible to imagine a definitive end-point and hence anyone actually "winning” in

\footnotetext{
${ }^{5}$ Having made a larger claim about the capacities of the espionage novel to map this new security landscape, I have chosen to focus on these three areas for the purposes of brevity and clarity but there is much more to be said about the genre's reflections on other aspects of this landscape; e.g. surveillance technologies, border controls, data-mining, the financial profiling of terror suspects etc.

${ }^{6}$ Jacques Rancière, “A Few Remarks on the Method of Jacques Rancière,” Parallax, 15 (2009), 122.

${ }^{7}$ Melley, 28
} 
a context of speculation. I see these espionage novel intervening in and responding to a larger transformation of the field of security, in which the old Cold War paradigm of clashing states, nuclear deterrents, spheres of influence etc. gives way to what Leander and van Munster call "the growing centrality of neoliberal governmentality." ${ }^{8}$ In this new landscape, security initiatives are outsourced, public-private partnerships are set up and citizens are "empowered" to become more resilient as citizensubjects. Indeed resilience is central to all aspects of this transformation, as it expresses "the capacity to positively or successfully adapt to external problems or threats." ${ }^{9}$ The extent to which these new aspects of speculation and resilience are reflected in works by Steinhauer and House, and how they are accommodated alongside the espionage genre's historical expressions of state sovereignty, is a key feature of this article. I am not suggesting that sovereign power disappears in this new security environment - or indeed in the espionage novel. Rather, I am interested in the ways it is re-imposed and re-imagined by multiple security actors and how this is reflected in the fictional works - itself part of a larger cross-disciplinary project to bring to bear some of the insights of critical security scholars on the analysis of literary texts and vice versa.

The espionage novel has never presupposed the successful realization of security. From the bomb that goes off in Joseph Conrad's The Secret Agent (1907) to the botched mission to infiltrate East Germany in John le Carré's The Looking Glass War (1965), the genre has always tempered notable successes at warding off disaster with such failures. What is different about more recent examples of the genre is their assimilation of failure into the security process. Rather than becoming the raison d'être of the entire story, as it is in The Looking Glass War (e.g. the mission is doomed to fail from the very beginning), failure is incorporated into the narrative at every point. In other words, failure is treated as an inevitable part of the process of speculating about and managing security risks and the incorporation of failure is central to the construction of resilience. This further engages with a distinction outlined by critical security scholars in the field of International Relations between "threat-based perspectives on security" which "rely on intelligence in an attempt to eliminate danger" and "risk" which "relies on

\footnotetext{
${ }^{8}$ Anna Leander and Rens van Munster, "Private Security Contractors in the Debate about Darfur: Reflecting and Reinforcing Neo-Liberal Governmentality,” International Relations , 21:2 (2007), 204.

${ }^{9}$ David Chandler, "Resilience and Human Security: The Post-Interventionist Paradigm," Security Dialogue, 43:3 (2012), 217.
} 
actuarial-like data, modelling and speculations that do not simply call for the elimination of risk but develop strategies to embrace it.” 10 "In short,” they continue, "whereas the concept of threat brings us to the domain of the production, management and destruction of dangers, the concept of risk mobilizes and focuses on different practices that arise from the construction, interpretation and management of contingency." 11 For my purposes, the "threat-based perspective on security" is reflected in the world of the Cold War espionage novel where the focus is on confronting and eliminating security threats via military and quasi-military means. This need to confront and eliminate is not entirely absent in more recent examples of the genre but it is now working alongside the concept of risk. That transition from threat to risk offers a useful way to think about the imaginative project of espionage writers like Steinhauer for whom the issue of speculating how and where future threats might materialize and representing how contingencies are managed becomes as central to the work as catching "bad guys". In a context of risk, older notions of paranoia, linked to a Cold War mentality of the "enemy" infiltrating one's ranks, are transformed into a more generalized uncertainty because the future is unknown and unknowable. In the espionage fictions considered here, this generalized uncertainty or anxiety becomes a consistent feature of the narrative precisely because the practices of speculating about what risks might exist are privileged over the resolutions being offered. It is also the case that espionage fiction, as opposed to history or sociology, is better able to capture this generalized uncertainty because the expression of anxiety goes right to the heart of what it is to be spy and indeed a human being in the kind of security environment that these works are trying to map.

\section{SPECULATION}

What is immediately striking about Steinhauer's trilogy of novels featuring CIA agent Milo Weaver is how short a time span they cover; three densely plotted, four hundred-plus page novels that essentially take place between July 2007 and July 2008. Relatedly, even if their collective touchstone is the

\footnotetext{
${ }^{10}$ Claudia Aradau, Luis Lobo-Guerrero and Rens van Munster, "Security, Technologies of Risk, and the Political,” Security Dialogue, 39:2-3 (2008), 148.

${ }^{11}$ Ibid., 148
} 
clandestine struggle between the US and China to secure their geopolitical and economic advantage domestically and across the globe, it is hard to differentiate what each novel is actually "about." Some time prior to the start of the first novel, The Tourist, elements within the CIA's top secret "Department of Tourism” arranged and carried out the assassination of pro-al-Qaeda Sudanese cleric Mullah Salih Ahmad and tried to implicate the Sudanese president and his Chinese paymasters in order to destabilise Chinese oil interests in the region. The novels trace the CIA's efforts to outmanoeuvre the Chinese, and the Chinese efforts to hit back and assert their own influence by damaging the US's security apparatus. In this sense, there is nothing particularly innovative about Steinhauer's trilogy. Despite Weaver's claim that the era of the Cold War has drawn to a close and that "[t]he other side was [now] multifaceted: Russian mafias, Chinese industrialization, loose nukes, and even the vocal Muslims camped in Afghanistan who were trying to pry Washington's fingers off the oil-soaked Middle East," ${ }^{12}$ the trilogy often retreats into a familiar bilateral frame of clashing sovereign powers. Here, the Soviet Union has been replaced by China as the US's pre-eminent global rival and the objective of the "game" is to secure the US's national interest and access scarce global commodities like oil. Part of how this is achieved, of course, is by gathering intelligence on the other side by placing moles in the upper echelons of their intelligence services in order to damage their capacity to act. The influence of le Carré's George Smiley novels is clear.

But to characterize these novels as straightforward generic rehashes is to miss their particular narrative inventiveness. For example, why condense so much plot into such a short temporal period? The short answer is that the three novels are effectively part of the same narrative; not necessarily a trilogy in a conventional sense (i.e. the multiple storylines and incipient tensions are tied together and resolved at the end of the third novel), but a single unfolding narrative, told from different points of view (albeit privileging Weaver's), where cause and effect do not map onto a clear trajectory towards some unequivocal end-point. It is easy to miss this point amidst the more familiar generic references. As described by Hepburn, these include the trafficking in secrets, the febrile atmosphere, flight in the face of danger (both from your side and the “enemy”), ambiguous allegiances "some declared, some

\footnotetext{
${ }^{12}$ Olen Steinhauer, The Tourist (London: Harper, 2010), 36. All subsequent citations refer to this edition.
} 
concealed,” the tempering of “ideology with personal motives” and the spy's multiple improvised identities. ${ }^{13}$ Overlaying this traditional generic architecture, however, is an effort to represent what Didier Bigo calls the "habitus" of a "professional security field"- a generalized security environment which encompasses the various US intelligence agencies (e.g. the CIA, Homeland Security), the German Federal Intelligence Service (BND), Britain’s MI5 and the Chinese Guoanbu. The inter- and intra-departmental rivalries expressed in the three novels reflect what Bigo calls a shared "sense of the game" whereby those involved "believe and act/react in a similar way even if they are always in competition." ${ }^{14}$ In part, of course, the focus on national intelligence agencies reinforces the genre's historical affiliations with the state and personal rivalries are not unconnected to states' geopolitical ambitions. The Nearest Exit, for example, depicts the multiple tensions between the BND and CIA through personal stories of blackmail, murder and smuggling. This security field or habitus is not the "great game" of the Cold War but a series of speculative manoeuvres on the part of its various players who, to quote Judith Butler, “make unilateral, unaccountable, pre-emptive security decisions” and who are "mobilized by aims and tactics of power they do not fully inaugurate or control." 15 This more heterogeneous, globally dispersed understanding of power driven by a preoccupation with multiple futures helps explain both what is "new" about current security arrangements and what is distinctive about Steinhauer’s narratives vis-à-vis earlier espionage novels.

If chess is an appropriate analogy to describe the gamesmanship of a novel like le Carré's Tinker, Tailor, Soldier, Spy (1974) whereby the moves and countermoves played out by Smiley and his Russian equivalent Karla are carefully designed to produce a winner and loser, what unfolds across Steinhauer's three novels is a good deal more inchoate and unpredictable. Because Steinhauer depicts the security threats to US interests as multiple and ubiquitous (e.g. from Islamic terrorists, contract assassins, Russian oligarchs, Moldovan gangs, Chinese spies and "rogue” elements in the CIA), he is also engaging in the broader risk management culture which, as Ulrich Beck argues, seeks to "feign

\footnotetext{
${ }^{13}$ Hepburn, xiv

${ }^{14}$ Didier Bigo, “Security and Immigration: Toward a Critique of the Governmentality of Unease,” Alternatives: Global, Local, Political 27 (2002), 75.

15 Judith Butler, Precarious Life: The Power of Mourning and Violence (London and New York: Verso, 2004), 56.
} 
control over the uncontrollable.” ${ }^{16}$ However, as critical security scholars have argued, if the ostensible goal of a risk society is to imagine and harness the uncertain future, dominant risk discourses are “categorically not about reducing risk, achieving control, or even about ensuring safety and security what matters...is that the appearance of securability and manageability is sustained." ${ }^{17}$ In Steinhauer's novels this appearance of securability is reflected in the endeavours of US intelligence analysts "hunched over computers, digging through mountains of information in order to write up their biweekly reports” (Tourist, 91). Their efforts should primarily be understood as part of a drive to shore up the Department of Tourism's shaky position vis-à-vis other competing intelligence agencies in a climate of "budget problems" and fiscal restraint. ${ }^{18}$ The same applies to 'twenty six clerks' of Xin Zhu's department in Beijing who sorted "through the news events of the day, through agents reports and intercepted communications," in order to buttress Zhu's authority. ${ }^{19}$ As an espionage novelist whose primary currency is frantic action, Steinhauer understandably struggles with the idea that the bureaucratic process of risk assessment, e.g. security experts staring at computer screens, might now be privileged in security circles over the interventions of field agents. Still, what he is keen to show, and what can be effectively shown in narrative fiction, is that both sides, the US and China, are using information they generate to speculate about the future - i.e. speculate how the future will be and whose speculations will prevail or pre-dominate - not as a way of reducing risk or achieving control over the uncontrollable but to prioritize decision-making in the present. ${ }^{20}$

The emphasis, then, is very much on assessing global risks rather than intervening to prevent. Indeed, the actual interventions by US and Chinese agents almost always lead to carnage because of contingencies that couldn’t have been foreseen by intelligence bureaucrats. Of course these "failures"

\footnotetext{
${ }^{16}$ Ulrich Beck, “The Terrorist Threat: World Risk Society Revisited,” Theory, Culture \& Society, 19:4 (2002), 4.

${ }^{17}$ Louise Amoore and Marieke de Goede, "Introduction," in Amoore and de Goede, eds., Risk and the War on Terror (Oxford and New York: Routledge, 2008), 9.

${ }^{18}$ Olen Steinhauer, The Nearest Exit (London: Corvus, 2011), 64. All subsequent citations refer to this edition.

${ }^{19}$ Olen Steinhauer, An American Spy (London: Corvus, 2012), 67.

${ }^{20}$ In this sense Steinhauer's speculations are better understood as premediations rather than risk calculations which are always future-orientated. De Goede notes that while risk and premediation 'proceed from a shared desire: to imagine, harness and commodify the uncertain future' premediation, unlike risk, 'is not about the future at all, but about enabling action in the present by visualizing and drawing upon multiple imagined futures'. See Marieke de Goede, "Beyond Risk: Premediation and the Post-9/11 Security Imagination,” Security Dialogue, 39:2 (2008), 159. Also see Richard A. Grusin, “Premediation,” Criticism, 46:1 (2004), 17-39.
} 
generate greater insecurity and therefore justify the further expansion of the intelligence agencies that presided over them. All of this has important implications for the kind of narrative that is possible under these circumstances. When projecting various threat scenarios becomes more important than identifying and eliminating the threats themselves, a flattened narrative structure is produced in which whereby the excessive high and low points of the more traditional espionage formula (e.g. heroic successes and noble failures) are smoothed out. Since it is not possible to imagine a single, vanquish-able enemy, and since threats are multiple and contingencies inevitable, it is difficult to imagine what total victory or failure, or indeed total security, look like. Hence, even those events that might otherwise look like victory or failure are assimilated into a flattened narrative that has no obvious end point because it is driven by a future that is always to come. For example, when Zhu turns the "tourists" against one another in The Nearest Exit and successfully orchestrates the murders of thirty three agents, his Chinese superiors treat it as an unwanted nuisance and the Americans, for the most part, take it as an opportunity to re-organize their security provision. In narrative terms, the event is significant and motivates a counter-action but it is not sensationalized; the deaths are not "seen" but are conveyed to intelligence analysts and us by the disappearance of dots on a screen. In other words, the event becomes but one incident in an ever-mutating narrative about the desire for security and the impossibility of ever actually achieving it, an ambivalence that the messiness of fiction, as opposed to the more cut and dried demands of historical analyses, is well suited to articulating.

In Steinhauer's 2011 short story “You Know What’s Going On” the notion that an Islamic terror cell, Aslim Taslam might be planning an attack in Kenya legitimizes pre-emptive action by the CIA. As with the Milo Weaver novels, the idea of "speculative security" is again shown to be hollow. Speculation on the part of the central CIA agent Sam Wallis may be about rendering the future actionable, but whatever action is taken by the CIA based on what they imagine might happen cannot accommodate contingencies in the present. These contingencies cannot be foreseen, in part because they are produced by the multiple counter-actions set in motion by other characters, including Nabil, one of the terrorists, trying to secure a radically different future. This dilemma is enacted by the complex structure of the story, told from different points of view and moving back and forth across time and space. This mosaic structure means that the "big picture" is only revealed in a piecemeal fashion as 
each new narrative is layered over the previous one in the manner of a palimpsest. Such formal parameters underline the extent to which no one is in control and that point to the limits of what can be known about the future under conditions of global uncertainty and deterritorialized power. "Tell me what's going on,” a bewildered CIA agent asks his African handler after he has been kidnapped from his hotel, to which the reply is, "You know what's going on" (39). Steinhauer's title is an ironic reflection on the new currency of intelligence and what can never be known in an age of constant speculation, and a comment on the impact of the unexpected and contingent, that this kind of fiction, with its constant switch-backing between different perspectives and its labyrinthine narratives where no one is in total control, is brilliantly able to realise, both in terms of form and content.

This short story, and the Milo Weaver trilogy, are attempts to delineate the limits of a security culture of risk and speculation and in doing so to normalize the traditional failures and successes that characterize espionage fiction. In Steinhauer's world, it is normal that efforts to bring about total security should result in exactly the opposite outcome. His stories are bound by, and bound up in, articulations about sovereignty in general and American sovereignty in particular- its character, its flaws, its limits. While the CIA might try to impose its own agenda on a highly volatile global situation, in order to buttress the US's national interests, its inventions produce exactly the opposite effect. As such, “You Know What's Going On?” forces us to think about the viability of the sovereign state's claim to exercise a monopoly of legitimate force within given spatial boundaries. In other words, what do sovereign borders mean in an era of increasing global mobility, as expressed by Steinhauer's efforts to connect events as diverse as disruption to shipping lanes, dwindling fish stocks, the development of new information technologies, offshore banking, the trans-continental threat from radical Islam, illegal arms shipments and leisure pursuits like cross-country car rally in Kenya? And what does monopoly mean when the CIA is striking up complex alliances with Somali fishermen, Kenyan political fixers, and jihadists in Europe and Africa? What kind of security is possible in such a context? I hesitate to describe this context as a post-sovereign one because Steinhauer does not fully wants to let go of the idea of the espionage story as an arena of clashing sovereign powers. However, in light of these questions, and this scepticism about the character and limits of sovereign power, it is sensible to explore how far he, and indeed the genre, is able or willing to push this line of thinking. To do this, I want to 
pay closer attention to Weaver himself and the issue of whether or to what extent the new security landscape and the formal innovations it has occasioned have produced a demonstrably different spy.

\section{RESILIENCE}

The first novel of the trilogy, The Tourist, opens with the line, "Four hours after his failed suicide, he descended toward Aerodrom Ljubljana” (3). Shortly after this, we are told that the still nameless protagonist "was a ludicrously unbalanced creature" (5) who frequently heard voices urging him "to take responsibility for his own death” (4). The subject traumatized by what he has seen or been forced to do is not uncommon in the genre and Weaver's suicidal urges are linked both to his immediate context (e.g. lying on the floor of a hotel room in Amsterdam protecting a Dutch politician as "the window exploded from automatic gunfire” 4) and, more subtly, to the larger geopolitical situation characterized by its lack of certainties and fixed co-ordinates. "There is no other side anymore," a fellow agent comments (35). This prologue takes place on the 10th and 11th September 2001 and while no reference to the terrorist attacks in New York and Washington DC is made in the narrative, the inference is clear: Weaver's personal crisis is linked to the national one. During the prologue's botched mission, Weaver is shot but precisely because he "was trained to follow through with actions even when faced with the unpredictable” (38-9) he is able to help a heavily pregnant woman caught up in the crossfire. Subsequently he marries her and adopts the child, and in The Nearest Exit, during a counselling session with her, he is able to reflect on the conjoined events. "My life had gone to hell, and I was desperate for something to hold on to... when I woke up next to Tina's bed, and we were watching the Towers on TV, I was more confused than anything else. I didn’t feel close to anybody” (346). By the present of the three novel, e.g. 2007-8, the US has, if not "bounced back" from the trauma of 9/11, had some time to come to terms with it, and Weaver's life, though still in periodic crisis, has stabilized, following his marriage and in part due to his ability to reflect on his situation put his life back into balance. Certainly there is no point in the trilogy where the suicidal yearnings of the first novel's prologue return.

It is this notion of Weaver as a resilient and self-aware individual that sets him apart from his generic antecedents. This is not to suggest that spies like James Bond and Jason Bourne are somehow 
not resilient. Very clearly they are able to endure significant hardships (physical exertion, violence, torture etc.) and still "bounce back.” But I do think that Weaver is resilient in a different way and that his capacities in this regard take on particular significance in light of an emerging body of crossdisciplinary scholarship on the subject of resilience. Brassett, Croft and Vaughan-Williams claim that resilience "is fast becoming the organising principle in contemporary political life" and that it now “occupies a central place in understanding and responding to a range of global uncertainties posed by high-impact low probability systems failures and traumatic events." ${ }^{21}$ In this respect, resilience is closely related to risk, i.e. making subjects and systems more resilient is an "integral part of the risk management cycle.” ${ }^{22}$ But whereas risk proceeds from the assumption that multiple futures can be imagined and perhaps hedged against, resilience is more focused on preparedness, so that when unforeseen traumatic events do occur, both individual subjects and the critical infrastructure of cities and states have the capacity to adapt. Brassett, Croft and Vaughan-Williams characterize the related transformation in the security landscape in terms of a move away from a sovereign or Cold War mindset in which “emergence planning...involved predicting events, isolating and relocating known threats, and protecting society using military and quasi-military means" to a context of post-sovereign governmentality where the burden of responsibility for managing risks and preparing for the unknown is shifted from the state to individuals, communities and businesses. ${ }^{23}$

Steinhauer's account of the contemporary security landscape and his depiction of Weaver as spy reflect some of these developments, and theorizations of these developments, but not always in straightforward and uncomplicated ways. The culture of emergency planning described above still prevails to some extent, certainly among the novels' intelligence chiefs, and speaks about Steinhauer's unwillingness to entirely relinquish a culture of security and operational planning forged during the Cold War. Nor is Weaver himself the product of the kind of new military environment, described by Alison Howell, where "resilience programming" has been sanctioned at the highest levels "to produce a fit fighting force in order to wage war more effectively" but also, in an age of austerity, "to reduce

\footnotetext{
${ }^{21}$ James Brassett, Stuart Croft and Nick Vaughan-Williams, "Introduction: An Agenda for Resilience Research in Politics and International Relations,” Politics, 33:4 (2013), 222.

${ }^{22}$ Ibid., 223.

${ }^{23}$ Ibid., 223.
} 
healthcare costs and entitlements by claiming to prevent mental health difficulties.” ${ }^{24}$ There is no such "enlightened” leadership at work in the security apparatus Steinhauer represents. However, in light of Weaver's self-directed efforts to transform himself from the suicidal, traumatized subject we see at the start of The Tourist to a man who willingly or otherwise subjects himself to counselling in order to get perspective on his marriage and who can be very insightful into his own predicament, and who is an asset to the security apparatus he often unwillingly serves, we cannot say he is not resilient in the way meant by Brassett, Croft and Vaughan-Williams. Certainly Weaver's resilience in the face of extreme adversity, e.g. his capacity to absorb physical punishment, is strongly evocative of his generic antecedents but it is also produced by efforts he has made to foster his own foresight and preparedness. As Julian Reid nicely puts it, "[s]ubjects that are capable of securing themselves are less of a threat to themselves and in being so are not a threat to the governance capacities of their states.” ${ }^{25}$ Typically the spy either has no recognizable domestic life (e.g. Bond) or his/her family commitments bridle against obligations to the job. Weaver's globe-trotting duties and the violence he unleashes, both willingly and unwillingly, because he has been ordered to do so, put enough of a strain on him to damage his capacities to lead a "normal" family life but it is the insights he gains about himself through interactions with family and via counselling sessions that, paradoxically, enable him to endure as a spy. But it is also the case that he is not the exemplary resilient subject of post-sovereign governmentality. Despite or maybe because of his capacities for critical self-reflection, he is not always operationally effective, i.e. he refuses to carry out certain orders, such as when he is tasked with kidnapping and killing a Moldovan girl in The Nearest Exit. While he is successful at exorcizing suicidal thoughts, he remains, at bottom, a man governed and at times paralyzed by anxiety, something that does, at certain points in the trilogy, make him a threat to himself and to others and in turn hints at the inadequacies of resilience planning as a form of (self)regulation. If there is an element of critique here, it is folded into a narrative, or a series of narratives, where the polemic is lost amidst an intimate and at times moving portrait of a

\footnotetext{
${ }^{24}$ Alison Howell, "The Ethics of Resilience: War, Austerity and Human Enhancement in the US Military's Comprehensive Soldier and Family Fitness Program,” Security Dialogue, published online 7 November 2014 http://sdi.sagepub.com/content/early/2014/11/06/0967010614551040 (accessed 12/11/14), 2.

${ }^{25}$ Julian Reid, “The Disastrous and Politically Debased Subject of Resilience," Development Dialogue, 58 (2012), 74.
} 
subject trying and at times failing to manage the extreme circumstances and contingencies of his life i.e. it is lost precisely because fiction is able to handle such careful portraiture better than political polemic.

\section{PROFIT}

Steinhauer's espionage fiction delineates some of the emerging aspects of the new security landscape, but its willingness to characterize the larger geopolitical situation primarily as a battleground between states means it cannot see this landscape in totality. Hence it is to Richard House's The Kills we need to turn in order to discern how sovereign power is being re-imagined by the state's parcelling out of security responsibilities to private contractors. In doing so, House hints at the ways in which the whole landscape of security is being transformed by these not-always-harmonious public/private partnerships and by the role of market in establishing priorities. Indeed the emphasis on protecting economic interests and chasing profits typically puts the private security provider at odds with the interests of the state. For the purposes of this article, I will focus on the first two books of the novel - "Sutler" and "The Massive" - since these are the ones that deal with the post-war reconstruction of Iraq and the complex links between private security and logistics contractors and US state agencies. Here it is less about the state losing control to or being usurped by corporations or, as Nikolas Rose and Peter Miller put it, about "accounting for government in terms of the 'power of the state"” but rather "of ascertaining how, and to what extent, the state is articulated into the activity of government" - i.e. "what relations are established between political and other authorities; what funds, forces, persons, knowledge...are utilized; and by means of what devices and techniques are these different tactics made operable.” ${ }^{26}$ In The Kills, the US government may provide the funds for the reconstruction efforts and it maintains a physical presence on the ground in Southern Iraq in the form of an agency called Southern-CIPA, but by tendering out the building of roads and administrative facilities and the training of personnel to a US-based private security multi-national called HOSCO - the Hospitality and Support Company of

\footnotetext{
${ }^{26}$ Nikolas Rose and Peter Miller, "Political Power beyond the State: Problematics of Government," British Journal of Sociology, 43:2 (1992), 177.
} 
Hampton Roads, Virginia - House shows, often in intricate detail, how the activity of government, broadly defined, and the setting up of procedures, systems and accountability, can be skewed to further a corporate agenda. In doing so, he moves the espionage form away a Cold War preoccupation with the state as protector towards an account of the consequences of the part-privatization of security and the state’s "hands-off” approach vis-à-vis its corporate partners - partners that are more interested in amassing profits than in contributing in a meaningful way to the reconstruction effort. By showing us how easily government systems and procedures can be breached - e.g. how large sums of money can be misplaced and/or embezzled - The Kills exposes the limits of resilience planning as a way of preparing for uncertainty and at the same time draws attention to the problems of entrepreneurialism as a mode or technique of governance.

At stake throughout this article is the extent to which the contemporary espionage novel is able to recognize and find ways of representing the dissolution of the old Cold War security paradigm and the attendant transformation of sovereignty. In The Kills, we don't necessarily see the hollowing out of the state in the face of hostile incursions from and by multi-national corporations. Instead the novel focuses on how state actors and private security contractors conspire to create a context where it is more important to imagine and project security threats (in order to mobilize action and of course funding in the present) than to do anything on the ground that might actually help to create a more secure environment. From the outset of the first book, the financial irregularities surrounding the reconstruction program are self-evident. "We had money ready for disbursement to HOSCO accounts sitting without movement,” Paul Howell, government representative, tells Paul Geezler from HOSCO. Then: "What started as a modest one-off loan to cover a shortfall quickly became a habit, and once he figured out a ruse, building roads through the desert no one would use, he saw no reason to stop himself.” ${ }^{27}$ In other words, a project earmarked for funding as part of the reconstruction effort building roads that no one will use - is entirely fictitious and operates as a ruse to cover embezzled and misappropriated funds; e.g. "backpacks, suitcases, briefcases, even brown-paper bags packed with cash” handed "to ministers, contractors, and project organisers” (9). Once discovered, instead of coming

\footnotetext{
${ }^{27}$ Richard House, The Kills (London: Picador, 2013), 8-9. All subsequent citations refer to this edition
} 
clean and admitting the error/crime, Geezler sets up another even more outrageous fictitious project the construction of an entire new city in the Iraqi desert - to account for the money that has been lost. Meanwhile the forensic investigation carried out by proxies for the US and fledgling Iraqi state fails to identify, let alone recover, the fifty million dollars that has been lost. The point is nicely made that the various actors involved in this effort are more interested in profit than security, and in maintaining the good name and share price of their corporations.

If we return to Rose and Miller's description of the state as a technique of government and expression of the arrangements between political and other authorities (e.g. in The Kills between Southern-CIPA and HOSCO), arrangements that utilize or seek to utilize government funds, forces, personnel, knowledge and importantly legitimacy, we can use this as the basis for imagining the neoliberal/security/governance nexus that House lays out for us. What we see are the contours of an entire system of governance, ostensibly subjected to resilience planning and with "robust" procedures in place to ensure probity and legitimacy - e.g. accounts with unique codes so that the transfer of funds can only be authorised by stated ex-officio individuals - and with an operational budget running into tens of millions. In fact, the resilience and legitimacy of this set up, connecting or indeed not connecting the US and the fledgling Iraqi states and multiple private contractors including HOSCO, is undermined from the outset. “There's a big fat disconnect between them and HOSCO. Neither really knows what's going on,” we are told (429). Ultimately culpability is not attributed to individuals but to a system where the quest for profit supersedes and even contradicts the interests of states and where slick presentations about supply chains, logistics and corporate compliance give way to 'real' stories of dysfunction, negligence and profiteering.

The question of what can be done in the face of this system which is both pervasive, perhaps even all-pervasive, and dysfunctional - neoliberalism reconstituted as criminality - is a pressing one, especially in light of what happens to the men HOSCO has hired to operate the "burn pits" in southern Iraq (i.e. where waste accrued from the reconstruction and military operation is illegally incinerated). In a more traditional espionage narrative, the "crime” would be uncovered by the spy-protagonist and culpability would be ascribed to a representative villain - and some kind of punishment or at least restitution would be meted out. The complexities of the situation that unfold in House's novel and his 
emphasis on victims rather than heroes and on systemic rather than individual culpability won't easily be accommodated in this kind of narrative. Instead he begins the second book of the novel with an account of those men, both military and private security personnel, who have died following their exposure to toxic carcinogens during the illegal burning of waste in Iraq. Initially we wonder whether Rem Gunnerson, a man hired by HOSCO to assess the building work in Iraq, might play the role of proxy spy and act to expose either the illegal "burn pits" or the larger fraud, but he is ineffectual. So too is his wife Cathy, despite her determination back in the US to stir up opposition to the illegal burning of waste and to confront HOSCO head-on. When she is told by a HOSCO employee that "all waste processing in southern Iraq is currently managed by Iraqi firms" and "responsibility for the health and safety of sub-contracted workers belongs to their employees” (456), any chance of holding the corporation liable for the "unexplained" deaths of the men who operated the "burn pits" evaporates. In fact the closest we get to a traditional hero is a minor player in the narrative, Luis Hernandez, a former soldier subsequently hired by HOSCO to work in Iraq, who takes direct action against his employer. At the start of the second book, before we know what has happened in Iraq, we're told that Hernandez 'abducted a man from his home, drugged him....and abandoned him, in a secure room without food and water' to die (251). The man in question turns out to be Geezler but Hernandez's vigilante action is not meant to position him as "hero"; rather the act is better understood as one of desperation. Geezler, House makes clear, is not the sole architect of what has gone wrong and hence the villain of the story. He is portrayed as a technocrat who has found vulnerability in the system and acts, out of corporate self-interest, to limit the damage. Instead the ire of the novel is directed at the system itself, at the laxness of corporate compliance and regulatory mechanisms, and at the ease with which corporations can re-brand themselves in order to distance them from accusations of mismanagement and carry on their operational work. Such a claim can't easily be accommodated in the structure of the traditional espionage narrative but House shows us how such narratives can be adapted to usefully reflect on the consequences, for individuals and institutions (public and private), of transformations in the security landscape. What House does make clear is that because individuals like Rem and Cathy can barely discern, let alone make sense of, the complex arrangements that link government and corporations, the 
likelihood of telling intervention, in order to publically attribute blame and mete out punishment, e.g. the job of the spy, is severely curtailed.

\section{CONCLUSION}

The claims made in this article about the capacities of the espionage novel and short story to represent and reflect on seismic changes in the security landscape, and to explore the limits of state sovereignty as an organizing category, are by no means totalizing ones. That's to say, the works considered here may reflect some of these changes through formal and thematic innovation but this is not to assume that they are representative of the contemporary genre at large which, I suspect, remains stubbornly tied to the older Cold War security paradigm. For example, Terry Hayes's I am Pilgrim (2014), which charts an attempt co-ordinated by the White House and carried out by a solo agent to thwart a cataclysmic small pox attack on US soil, more closely incorporates this paradigm and the generic norms attendant on it - e.g. whereby a specific terror threat is identified and eradicated via the specialized knowledge and expertise of the solo actor. Nor am I arguing that Cold War espionage novels are unable to critically reflect on their own security environment. John le Carré's entire oeuvre is testament to this point. However my concluding remarks on Richard House's The Kills do raise the question of what kind of resistance is possible in a genre like the espionage novel which has always been tainted with its associations with power, either that of the state or power in a more dispersed, postsovereign form. Given Milo Weaver's insider status and his uneasy collusion with the people and hierarchies that establish the terms of his actions, it is hard to see who or what he is trying to resist. Weaver's wariness or ambivalence could, I suppose, constitute a muted form of protest. The Kills, meanwhile, suggests that, for all its flaws, the current dispensation of public/private partnerships and profit-over-security will continue. But by “reframing forms of experience,” to quote Rancière, or rather by laying bare the hidden contours of this system and more importantly showing us the human costs (e.g. illness, death) suffered by individuals as a result of the corporatization of security, it is instructive how closely House's moves resemble what Michel Foucault calls "counter-conduct.” Not the direct performing of political action, as Rancière would have it, but "a much more diffuse and subdued form 
of resistance" which is tied to the thing, the system or the mode of governance being resisted. ${ }^{28}$ Perhaps, though, it is not House's novel per se that evokes Foucault's definition but the espionage genre in general, whatever kind of security landscape is being mapped. This, then, is the challenge and burden of the espionage novelist and indeed the spy: how to come to terms with the nature and effects of power as it is exercised in the pursuit of security without being subsumed by it. And it is the "reframing" of the ambivalence of this particular experience that gets to the heart of what fiction can do so well.

${ }^{28}$ Michel Foucault, Security, Territory, Population: Lectures at the Collège De France 1977-1978, ed. Michel Senellart, trans. Graham Burchell (Basingstoke: Palgrave, 2007), 200. 